Pakistan Journal of Education

Vol.38, No.2, 2021, 91-131

\title{
Psychometric Testing and Semantic Validation of ISPCAN Child Abuse Screening Tool (ICAST) in Urdu Language
}

\author{
Rabia Iftikhar* \\ Farah Malik $^{* *}$
}

\begin{abstract}
ISPCAN Child abuse screening tool (ICAST) has been used broadly for measuring maltreatment against children. The present study aimed to translate and validate the Child Abuse Screening Tool for two main purposes. Firstly, this scale was translated to use it as a screening tool for the abused children. Secondly, to determine concurrent validity of indigenous Child Abuse Scale (Malik \& Shah, 2007) Revision by Malik and Saeed (2014). The Child Abuse Scale Revised was altered to address issues related to child abuse and sexual abuse in educational institutions, home, workplace, by relatives, strangers and servants. A sample of 100 children with age range 9 to 14 years $(M=12.08$; $S D=1.47) 50$ boys and 50 girls were drawn from 2 mainstream schools of Lahore city by using convenient sampling for validation of the scale. The scale was translated using standardized procedure of forward and backward translation by Mapi guidelines (2012). Confirmatory factor analysis was run to examine the factorial structure of Urdu translated scale on a new set of data comprised of 200 children with equal gender ratio between 9 to 14 years $(M=12.19 ; S D=2.53)$. The results of CFA show adequate model fit; supporting the five-factor solution of original scale. Thus, reliability and validity analysis indicated that the Urdu translated CAST scale is a valid and reliable tool for screening abused children in Pakistan.
\end{abstract}

Keywords: abuse, translation, validity, child maltreatment, Urdu

\footnotetext{
Assistant Professor, Clinical Psychology Unit, Department of Psychology, GC University, Lahore, Pakistan. Email: rubail1983@gmail.com

** Professor, Institute of Applied Psychology, University of the Punjab, Lahore, Pakistan. Email: drfarahmalik@gmail.com
} 


\section{Introduction}

For the past 20 years, physical, sexual, psychological abuse, neglect and violence against children has become more evident internationally. There is no common consensus developed yet on definition of child abuse, and this definition varies from culture to culture. However, an agreement has been made on the definition of severe forms of child abuse such as sexual abuse (Pierce \& Bozalek, 2004; Lalor, 2004). A number of researches show that child abuse is not commonly reported. Forrester and Harwin (2000) in one of their articles threw light on the sad reality that so far very few accurate and reliable measures are available that can guage the degree of child abuse in the world.

Childhood abuse has been found to be a powerful predictor both at social and environmental level that can be a leading risk factor of death and disability at any stage of life (Silveira \& Grassi- Oliveira, 2016). In a recent research compilation neglect and childhood abuse are reported to be more common in countries that are struggling with cultural influences, development and economical issues. (Silveira \& Grassi-Oliveira, 2016). Child abuse is under reported and under recorded in history. Alongside, physical punishment has been viewed as a normal disciplinary practice by majority of the people. (Silveira\&Grassi-Oliveira,2016). Child abuse includes any act of commission or omission against a child which negatively effect his/ her emotional or physical health(Anderson, 2008) (pp. 197-211).According to Gilbert, Wisdom, Browne, Fergusson, Webb and Janson (2009) child abuse-related statistics found in high-income countries remain a major problem. Annually, about $4-16 \%$ of children become victims of physical abuse and one in ten suffer from physical or psychological abuse. It also revealed that girls are twice as likely to be sexually abused than boys during childhood. In addition, in 2013 as per U.S. Department of Health and Human Services (DHHS) reports approximately 80,000 children were abused or ill-treated. $18 \%$ of the cases reported were of physical abuse.

Developing countries also demonstrated a negative picture. In a recent article in The Sunday Leader written by Trivedi (2013) states that in Sri Lanka, child abuse has reached a high level. The statistical data from the Sri Lankan Department of Justice revealed that about 15,000 tests are pending nationwide, with more than $27 \%$ involving some form of violence towards a child. The numbers are even higher in rural areas where almost half of Colombo's cases were related to child abuse alone.

The occurrence of child sexual maltreatment in Asia goes from $3.3 \%-42.7 \%$ for females in China and India individually and 4.3\%-58\% for males in Hong Kong and Sri Lanka. The rates for contact CSA among 
females in Asia are from 1.9\%-59.2\% in China and India and 1.8\%-9.1\% for males in China while for non-contact abuse goes from 1.8\%-28.7\% for females in China and India and 3.1\%-29.4\% for males in China (Selenga, Thuy, and Mushi, 2020).

The prevalence of child maltreatment and violence in Pakistan is increasing gradually. Each day 10 children are being sexually abused in year 2015 making a total of 3,768 as reported by the Society for the Protection of Children's Rights (SPARC, 2015). As reported by SPARC 1,225 cases of sodomy were reported that were inclusive of gang-rape and gang sodomy, in addition to that there were 258 incidence of attempted rape / sodomy, gang-rape and gang sodomy. Overall, at least 142 victims were murdered after being sexually battered. A detailed examination of the issue revealed that $8 \%$ of sexual assault victims were between the ages of 6 and 10, 26\% were in the age range of $11-15$ years, and $11 \%$ were between the ages of 16 and 18. A few victims were babies of one-year age. Regarding various forms of sexual abuse, a UNICEF (2016) report states that 755 victims were tortured after a burglary, 313 were raped, 147 were abducted, 100 were raped by criminals, 94 survived rape, 63 were raped by criminals, and 53 were victims of abuse child marriages (UNICEF, 2016).While the ratio of urban and rural child abuse cases was 33 to 67 percent in the country, with majority of the cases $(2,054)$ cited in Punjab, with 875 cases in Sindh, and 297 took place in Balochistan, there were 152 in Khyber Pakhtunkhwa and 90 in Islamabad, 38 in Azad Jammu and Kashmir, one each in Gilgit-Baltistan and the federally administered tribal agencies(National Statistics on Child Abuse, 2015). A recent number of child sexual maltreatment in Pakistan is reported by the non-government organisation SAHIL's annual report on "Cruel Numbers" estimated out of 2960 cases, 1510 girls and 1450 boys are sexually abused in gang rapes, sodomy and abduction in 2020.

It is important here to discuss types of child abuse:

i. Physical Abuse: Physical abuse is defined in terms of legal and cultural differences across communities that may or may not include certain types of punishment as form of abuse. In many parts of the world, beating a child for his/ her behavior is not considered as form of physical abuse Smith (2016). In addition, there are certain cultures that do not consider even the most severe forms of physical punishment as abuse but there are other cultures that do not tolerate even the slightest pain inflicted to children. According to WHO (2002) physical abuse of a child is any act made by the caretaker of the child that may harm the child or have the propensity to harm him. Mistreatment leading to physical harm or psychological 
damage to the child is regarded as physical abuse. According to another report by the (U.S. Department of Health and Human Services, 2016) the presence of physical abuse was found to be 49 in every 1000 children. This include certain behaviors such as stabbing a victim, assaulting him/ her or threatening with the use of a sharp object or any weapon.

ii. Verbal Abuse: Verbal abuse is the use of inappropriate statements when parents try to stop a child's behavior, to bring order and control the child. Excessive use of verbal abuse by parents is damaging to child's emotional and mental health. Verbal abuse should be prevented when a child's behavior need to be stopped (Howard, 1996; Lamper, 2003; McKay, Fanning, Paley, \& Landis, 1996; Walker, 2003). Studies on verbal abuse are relatively small and more recently experts have begun to examine the effects, frequency, and predictors of verbal abuse. Details of the various effects of verbal abuse on children suggest that children exposed to parental abuse face various problems such as low self-esteem, negative attitudes toward the outside world and negative self-esteem (Ney, 1987). As adults, they have a tendency to create conflict and grief (Kent \& Waller, 1998; Rich, Gidycz, Warkentin, Loh, \& Weiland, 2005), identity issues (Johnson et al., 2001; Teicher et al., 2006), issues related to language adjustment (Teicher, Samson, Tomoda, Ashy, \& Andersen, 2007), and have poor health habits (Hillis, Anda, Dube, Felitti, \& Marchbanks, 2004; Williamson, Thompson, Anda, Dietz, \& Felitti , 2002).

iii. Emotional Abuse: There might be a remedy for physical abuse or physical pain, but psychological wounds last for years. According to The World Health Organization, emotional abuse is the caretaker's failure to provide proper care, attention and nurturing environment to the child. It also includes actions that has a negative impact on psychological well-being and development. Emotional abuse also includes rejection that is when a parent or caretaker refuses to recognize the needs and worthiness of the child (Olive, 2007). Terrorizing the child has been linked with emotional abuse as it involves verbal assault of parents to the child which scares the child. Other forms of emotional abuse include isolation where the parent prevents the child from making friends and has a normal social life. Emotional abuse includes traumatic acts e.g. preventing a child thus restricting his activities, humiliating and laughing at him, frightening and disturbing the child, rendering judgment to the victim, denying love to them and any other unsympathetic behavior (World Health Organization, 2002). 
iv. Sexual Abuse: According to the (World Health Organization, 2002) sexual abuse has been defined as the act by the caregiver in which he/she tries to exploit the child for sexual pleasure. Olive (2007) describes sexual abuse as an act that happens between a child and an adult where the adult receives some form of sexual gratification. Many actions are involved in sexual abuse for instance kissing a child's lips or tongue, touching a child's genitals and breasts \& genitals and penetrating sex such as oral, anal or vaginal etc. Sexual abuse is a complex form of abuse that brings remorse and shame to the victim. It is noteworthy, however, that sexual abuse is not always linked to physical contact which means that sexual abuse can also be performed without physically affecting the child. In this regard, it has been proposed by Baker and Duncan (1985), that when a sexually mature person engages with a child under the age of 16 , in a certain type of misconduct that can lead to sexual arousal on the part of an adult is also called sexual abuse. Over the time, the definition of sexual abuse has been segmented into contact and noncontact abuse. Contact abuse involve acts where touching is involved for instance kissing, touching, sexual intercourse. Whereas, noncontact sexual abuse includes activities where touching is not involved for example pornography, sexual talk which sexually provokes the adult. Sexual abuse includes a wide area from adults that exposes their body to the children to penetrative sex.

v. Neglect: Child neglect is described as the ignorance of the parent or caregivers in the provision of appropriate social, emotional, biological needs, need for love and belongingness even though the child is in an position to do so (World Health Organization, 2002). Thus, neglect cannot be justified with poverty because it occurs when the child is abandoned despite sufficient availability of resources. Neglect was referred as passive abuse by Flangan (1998). Child neglect cam take many forms such as physical neglect, emotional neglect, educational neglect, and medical neglect. The caregiver's inability to provide warmth, comfort, nourishment and emotional security is called emotional neglect. This may increase the child's feelings of loneliness and therefore child feel difficulty establishing relationships and bond with other people. Therefore, lack of intimacy between the child and parent or caregiver leads to mental health issues such as depression, sadness, isolation, difficulty socializing. 
Children are abused psychologically, physically and socially every day in their homes, communities and schools (Pinheiro, 2006). Society for the Protection of the Rights of Children (SPARC) has reported an increasing rate of child abuse and violence against children in Pakistan. Furthermore, it states that ten children per day were sexually abused in 2015 reaching a total of 3,768 children (DIC Multan At A Glance (As of December 2014). Early exposure to abuse is related with lasting negative effects on physical, social and psychological health of children and the negative impact of these factors continues to adulthood (Hoft \& Haddad, 2017; Meinck et al. 2018). Different forms of abuse are physical, verbal, emotional, neglect and sexual.

A number of surveys have been done regarding corporal punishment given to children in schools by teachers and other care takers. Beating, kicking, hitting and punching are the forms of corporal punishment that frequently occur in schools and other institutions for young offenders (Finkelhor, Ormrod, Turner \& Hamby, 2005). Lakhdir et al. (2017) reported the findings with Pakistani sample that a male child is five times more likely to be mistreated than a female child. Corporal punishment has been commonly used by parents before mid-1960. They consider corporal punishment as a means to observe discipline in children rather than a cruel act. Moffatt (2003) suggested that any kind of punishment that left a mark on the child is considered abusive.

Convention on the Rights of the Child (CRC) states that it is the obligatory duty of every state to protect children from all kinds of child maltreatment. Corporal punishment was banned for the first time in Sweden. Only four states of Asia have banned corporal punishment namely Nepal, Mongolia, Israel and Turkmenistan (Haque et al, 2019). Child abuse has a long-term and deep-rooted impact on social, emotional, biological and psychological development of the child. According to Herman (1997), child abuse has a daunting impact on the child's personality. Gabbay, Oatis, Silva \& Hisrch (2004) in their study found that $20-63 \%$ of abused children have a predisposition to develop posttraumatic stress disorder in adulthood and they may exhibit aversive attitude. Children who are abused have poor emotional regulation than non- abused children (Goodman, Quas \& Ogle, 2010). Dysthymia and depression have been reported in sexually maltreated children (Homor, 2010; Wozencraft, Wagner, \& Pellegrin, 1991). Berliner and Elliot (2002) suggest that children who survive sexual abuse have 5 times greater chances of suffering from anxiety disorder. Alcohol consumption or addiction has also been reported in sexually victimized children (Brown, 2012). Sexually mistreated children are likely to commit suicide or engage in self-injurious behaviors (Joiner et al, 2007). 
International Society for the Prevention of Child Abuse and Neglect (ISPCAN) and UNICEF work in collaboration to investigate about occurrences of abuse against children throughout the world. The ICAST was developed after two rounds of Delphi review (Runyan, Wattam, Ikeda, Hassan \& Ramiro, 2009). It has been translated and validated into at least 20 languages. The strength of ICAST lies in its cross- cultural application (Meinck et al 2018). The child version of ICAST is comprised of two sections that is, home victimization and institutional victimization. The home victimization section has 38 items constituting five subscales: "physical abuse, physical punishment, sexual abuse, psychological abuse and neglect". On the other hand, institutional victimization has 44 items with 3 subscales: "psychological victimization, sexual assault, physical assault". Only one study outlines the psychometric properties of ICAST (Zolotor et al., 2009).

The ICAST is translated in several countries and validated in several languages for example Spanish, Hindi, Icelandic, Russian, Malay and Portuguese (Dune, Zolotor, Runyan, Andrewa-Miller, Choo, Dune et al. (2009). The ICAST addresses questions related to physical, sexual and emotional events, questions about perpetrator, frequency and characteristics of acts. Psychometric analysis in the ICAST-C have been carried our earlier. They report good internal consistency $(\alpha>.70)$ for physical abuse, sexual abuse, psychological abuse and neglect sub-scales. Whereas, it has fair internal consistency $(\alpha=.69)$ for the violence exposure scale across a sample of 571 adolescents collected from Colombia, India, Russia and Iceland (Zolotor et al., 2009). Similar internal consistency for ICAST sub-scales have been reported in studies with 1028 adolescents in Lebanon, 1142 adolescents in Romania and 5236 adolescents in Taiwan (Meinck et al 2018). The construct validity of ICAST was examined in Taiwanese study by using confirmatory factor analysis (CFA). Model fit statistics suggested adequate fit among constructs with medium $(r=.47)$ to large $(r=.81)$ correlations except for sexual abuse and neglect $(r=.23)$ (Meinck et al 2018).

In accordance with previous studies, a Chinese Version of CAST was translated on a random sample of 5236 adolescents from 35 schools of Taiwan. The content validity and semantic equivalence of translation was satisfactory. Furthermore, the CFA also confirmed the five-factor solution of CAST (Chang, Lin, Chang, Tsai \& Feng, 2013). Another study conducted in Brazil suggested that children showed difficulty in understanding 7 items out of 69 . These items were adapted according to the Brazilian culture while maintaining their conceptual and idiomatic equivalence. The results revealed adequate internal consistency and validity of Portuguese Brazilian version of the ICAST (Silveira \& GrassiOliveira, 2016). 
A study conducted in Malaysia aimed to translate and validate ICAST in Malay language. The analysis of study revealed that Malay version had high total score internal consistency that is, Cronbach alpa of 0.84 but had low internal consistency on subscales (ranging between 0.61 to 0.81 ). The study failed to establish adequate reliability and validity of ICAST Malay version (Sahaimi, 2016).

Another study conducted in Bangladesh successfully translates ICAST in Bengali language. Child physical abuse was reported to be extremely high in rural areas of Bangladesh (Haque et al., 2019). Irrespective of its extensive use, literature suggests that the scale lack psychometric evaluations. Therefore, the present study aims to translate and adapt ICAST in Urdu language and validate its semantic equivalence to measure the degree of different dimensions of child maltreatment in Pakistan.

\section{Research Methodology}

This study comprised of three phases, first phase was translation and validation of the scale by using standardized procedure of MAPI Guidelines (2012). The second phase examined the factorial structure through confirmatory analyses (CFA) and third phase focused on the validation of the scale.

\section{Phase I: Translation \& Adaptation}

ISPCAN Child Abuse Screening Tool (ICAST) (Runyan et al., 2009): The CAST consisted of 34 items having five subscales namely physical abuse, psychological abuse, physical punishment, neglect and sexual abuse. The scale is to be used with children having age range between $11-17$ years. Home victimization component of the scale has internal consistency reliability as follows: home exposure to violence 0.69 ; physical abuse 0.77 ; psychological abuse 0.78 ; sexual abuse 0.72 ; and neglect 0.86 . While, institutional victimization section of the tool has internal consistency reliability as follows: physical victimization 0.85 ; psychological victimization 0.86; and sexual victimization 0.78 (Zolotor, et al., 2009). The Urdu translation of scale was preceded after approval of original authors by keeping the standardized produce of translation and adaptation in consideration.

\section{Step I: Forward Translation}

Initially, English to Urdu translation was done by 3 bilingual experts. The experts were given instructions to translate the items while retaining their conceptual essence rather than literal meaning. They were also asked to consider the age of participants while doing translation. 
Step II: Reconciliation of Items. Three independent forward translations were compared and assessed in terms of best translation on the basis of conceptual equivalence, clarity and comprehensibility by the translation committee comprised of scholar and the supervisor. The assessment of each item was documented and also vetted in terms of cultural and linguistic connotations by the experts.

\section{Step III: Backward Translation}

Reconciliation of items was done by translation committee comprised of experts and the supervisor on the basis of conceptual equivalence and comprehensibility. Then, the reconciled forward translation was given to 2 bilinguals for translating it from Urdu to English (Backward translation). The backward translation was also evaluated, and it was same as original scale in language and semantic equivalence.

\section{Step IV: Pre-Testing}

The comprehensibility and conceptual clarity of each item was verified by conducting cognitive interviews with 20 children of 9 to 15 years of age. The children could easily read and understand all the items. After pretesting, inter item correlation was calculated using Pearson Product Moment which was above .7 for all items showing highly significant relationship between original and Urdu version.

\section{Step V: Empirical Evaluation}

Finally, the validation of the scales was analyzed by exploring the psychometric properties and structure of the factors explained originally by ICAST on Pakistani children and to generalize the results of the validation study to this population.

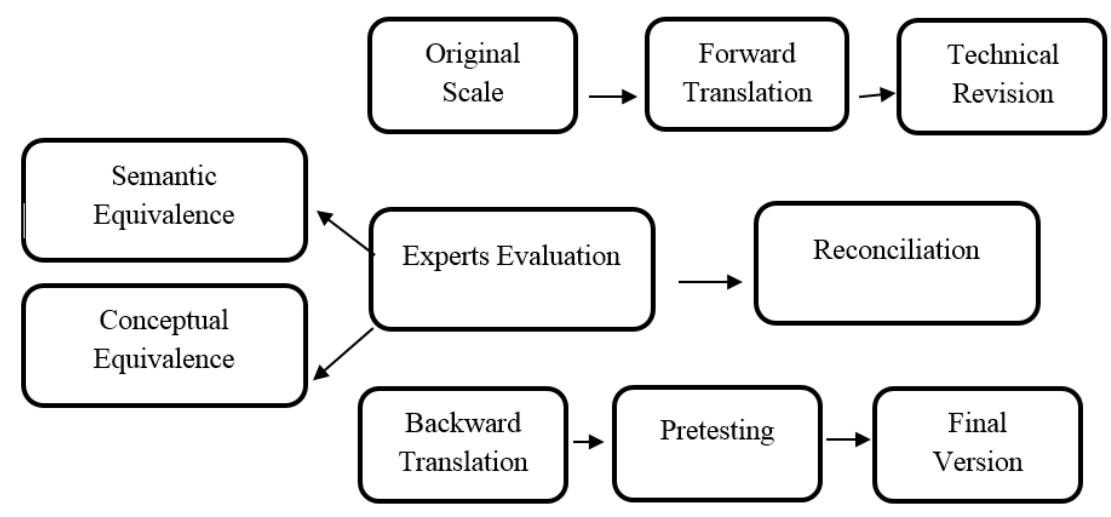

Figure 1. Flowchart: Translation and adaptation of ICAST 


\section{Procedure}

Written permission was taken from the mainstream school of Lahore city and authorities were briefly explained about the rationale of the study. Informed consent was signed by the parents of children before their participation in the study. Confidentiality was ensured and the participants were given the right to withdraw at any time. The questionnaire was filled by the students in their regular class timings. Additionally, children who got emotionally disturb after asking personal questions related to abuse were referred for counseling services.

\section{Phase II: Factorial Structure}

\section{Participants and Design}

A sample 200 (100 boys and 100 girls) with age ranges between 9 to 14 years $(M=12.19 ; S D=2.53)$ were drawn from mainstream schools of Lahore by using convenient sampling technique. Participation was voluntary and confidentiality of participants was maintained.

\section{Confirmatory Factor Analysis}

The confirmatory factor analysis (CFA) was used to analyze the model fit of present data to the proposed factors of CAST, based on original theory and preceding research findings on 200 children. Table 1 shows the fit indices of ICAST in new sample. The result revealed adequate to reasonable model fit of five- factor model, $x^{2}=1607.77(d f=$ $550, N=200), p<.05$, RMSEA $=.06, \mathrm{CFI}=.92, \mathrm{GFI}=.92$ AMD TLI $=.91$. Hence, overall results indicate the support of five-factor model of CAST. The chi square has significant value due to greater degree of freedom; therefore by "dividing degree of freedom by chi-square $\left(x^{2} / d f\right)$ the value is 2.92 which is acceptable for model fit $(\mathrm{Hu}$, Bentler \& Kano, 1992).

The table 2 shows the standardized factor loadings of CAST on confirmatory factor analysis of five factor solution which is consistent with the original scale measurement model. The range of factor loadings was within .30 to .99 , which were significant. There were two items (39 and 40) with relatively low loadings ranging from .24 to .30 .

Table 1

Fit Indices of 5- Factor Model of Child Abuse Screening Tool

\begin{tabular}{lccccc}
\hline Model & $x^{2}$ & RMSEA & CFI & GFI & TLI \\
\hline 5-Factor Solution & 1607.77 & .06 & .92 & .92 & .91 \\
\hline
\end{tabular}

Note: $p<.05, d f=550$ 
Table 2

Standardized Factor Loadings of Confirmatory Factor Analysis Model for the Child Abuse Screening Tool $(N=200)$

\begin{tabular}{|c|c|c|c|c|c|}
\hline \multirow[t]{2}{*}{ Items } & \multicolumn{5}{|c|}{ Factor Loadings } \\
\hline & $\begin{array}{l}\text { Factor } 1 \\
\text { (Physical } \\
\text { discipline) }\end{array}$ & $\begin{array}{c}\text { Factor } 2 \\
\text { (Psychological } \\
\text { Abuse) }\end{array}$ & $\begin{array}{l}\text { Factor } 3 \\
\text { (Neglect) }\end{array}$ & $\begin{array}{c}\text { Factor } 4 \\
\text { (Physical } \\
\text { Abuse) }\end{array}$ & $\begin{array}{c}\text { Factor } 5 \\
\text { (Sexual } \\
\text { Abuse) }\end{array}$ \\
\hline Item 11 & .85 & & & & \\
\hline Item 12 & .92 & & & & \\
\hline Item 13 & .97 & & & & \\
\hline Item 14 & .87 & & & & \\
\hline Item 15 & .86 & & & & \\
\hline Item 16 & .88 & & & & \\
\hline Item 17 & .92 & & & & \\
\hline Item 18 & & .89 & & & \\
\hline Item 19 & & .96 & & & \\
\hline Item 20 & & .85 & & & \\
\hline Item 21 & & .79 & & & \\
\hline Item 22 & & .87 & & & \\
\hline Item 23 & & .91 & & & \\
\hline Item 24 & & .31 & & & \\
\hline Item 25 & & .66 & & & \\
\hline Item 26 & & & .75 & & \\
\hline Item 27 & & & .76 & & \\
\hline Item 28 & & & .87 & & \\
\hline Item 29 & & & .95 & & \\
\hline Item 30 & & & .87 & & \\
\hline Item 31 & & & .86 & & \\
\hline Item 32 & & & & .81 & \\
\hline Item 33 & & & & .86 & \\
\hline Item 34 & & & & .92 & \\
\hline Item 35 & & & & .86 & \\
\hline Item 36 & & & & .45 & \\
\hline Item 37 & & & & .86 & \\
\hline Item 38 & & & & .70 & \\
\hline Item 39 & & & & .28 & \\
\hline Item 40 & & & & .29 & \\
\hline Item 41 & & & & & .96 \\
\hline Item 42 & & & & & .99 \\
\hline Item 43 & & & & & .99 \\
\hline Item 44 & & & & & .39 \\
\hline Item 45 & & & & & .99 \\
\hline
\end{tabular}

\section{Phase III: Validation Study}

\section{Participants and Design}

A sample of 100 children with age range 9 to 14 years $(M=12.08$; $S D=1.47$ ) 50 boys and 50 girls were drawn from 2 public schools in Lahore city. Children participated on voluntary basis. 


\section{Results}

The data was analyzed using Statistical Package for the Social Sciences (SPSS 16 Version) and Analysis of a Moment Structures (AMOS 19 Version) for descriptive and inferential statistics.

Table 3

Psychometric properties of the Translated Child Abuse Screening Tool (CAST) and its Subscales $(N=100)$

\begin{tabular}{lccl}
\hline Measure \& Subscales & $k$ & $M(S D)$ & $a$ \\
\hline CAST Total & 35 & $24.93(26.35)$ & .97 \\
Physical Discipline & 7 & $4.21(4.75)$ & .78 \\
Neglect & 6 & $4.72(6.05)$ & .92 \\
Psychological & 8 & $6.55(7.66)$ & .91 \\
Physical & 9 & $6.32(7.06)$ & .82 \\
Sexual abuse & 5 & $3.10(5.23)$ & .93 \\
\hline
\end{tabular}

Note: $k=$ Number of items, $M=$ Mean, $S D=$ Standard Deviation, $a=$ Cronbach's alpha

Table 3 indicates the reliability of Urdu translated Child Abuse Screening Tool (CAST). The translated Urdu Child Abuse Screening Tool is comprised of five subscales: Physical discipline, psychological abuse, neglect, physical abuse, and sexual abuse. The results show significantly high reliability of all the subscales of Urdu CAST on population of 100 Pakistani local children.

Table 4

Correlation Matrix for the Child Abuse Screening Tool (CAST) and Subscales $(N=100)$

\begin{tabular}{lcccccc}
\hline Subscales & 1 & 2 & 3 & 4 & 5 & 6 \\
\hline 1.CAST Total & - & $.88^{* *}$ & $.88^{* *}$ & $.91^{* *}$ & $.92^{* *}$ & $.55^{* *}$ \\
2.Phys Disci & - & & $.86^{* *}$ & $.92^{* *}$ & $.90^{* *}$ & $.22^{*}$ \\
3.Neglect & - & - & - & $.92^{* *}$ & $.92^{* *}$ & .18 \\
4.Psychological & - & - & - & - & $.91^{* *}$ & $.21^{*}$ \\
5.Physical & - & - & - & - & - & $.25^{* *}$ \\
6.Sexual abuse & - & - & - & - & - & \\
$M$ & 39.15 & 4.21 & 4.72 & 10.38 & 11.28 & 8.54 \\
SD & 40.41 & 4.75 & 6.05 & 12.02 & 12.91 & 14.27 \\
\hline
\end{tabular}

Note: Phys Disci $=$ Physical Discipline, ${ }^{*} p<.05,{ }^{*} p<.001$.

Table 4 illustrates the result of inter-correlation matrix between ICAST and its subscales. The results show significant correlation between all the five subscales of ICAST and total ICAST scale $(p<.001)$. The subscales are found adequate to screen abused children. All the subscales of CAST correlate significantly with each other except sexual abuse and 
neglect subscale $(p<.05)$. Moreover, physical discipline and psychological abuse subscale correlate significantly positively ( $r$ $=.22, .21 ; p<.05$ respectively) with sexual abuse subscale.

Table 5

Validity (Convergent and Discriminant) of the Child Abuse Screening Tool (CAST; $N=100)$

\begin{tabular}{lccccc}
\hline Variables & 1 & 2 & 3 & 4 & 5 \\
\hline 1.CAST Total & - & $.78^{* *}$ & $.74^{* \star}$ & $-.59^{* *}$ & $-.55^{* *}$ \\
2.CAS-F Total & - & - & $.89^{* *}$ & $-.58^{* *}$ & $-.58^{* *}$ \\
3.CAS-M Total & - & - & - & $-.63^{* *}$ & $-.62^{\star *}$ \\
4.Optimism (EQ) & - & - & - & - & $.77^{\star *}$ \\
5.Happiness (EQ) & - & - & - & - & - \\
M & 39.15 & 73.70 & 70.86 & 20.21 & 14.66 \\
SD & 40.41 & 28.69 & 23.81 & 6.05 & 3.75 \\
\hline
\end{tabular}

Note: CAST Total $=$ Child Abuse Screening Tool Total; CAS-F Total $=$ Child Abuse Scale-Father Total; CAS-M Total = Child Abuse ScaleMother Total; $\mathrm{EQ}=$ Emotional Intelligence, ${ }^{* *} p<.001$.

Table 5 describes the convergent and divergent validity of Child Abuse Screening Tool with CAS- R father and mother form, and optimism and happiness subscales of Emotional Intelligence scale. The results indicate that ICAST shows positive correlation with CAS-F and CAS-M ( $r=.78, .74 ; p<.001$ respectively), showing high convergent validity of CAST. Moreover, a significant negative correlation was found between ICAST and subscales of EQ scale that is, Optimism and happiness ( $r=$ $-.59,-.55 ; p<.001$ respectively). 


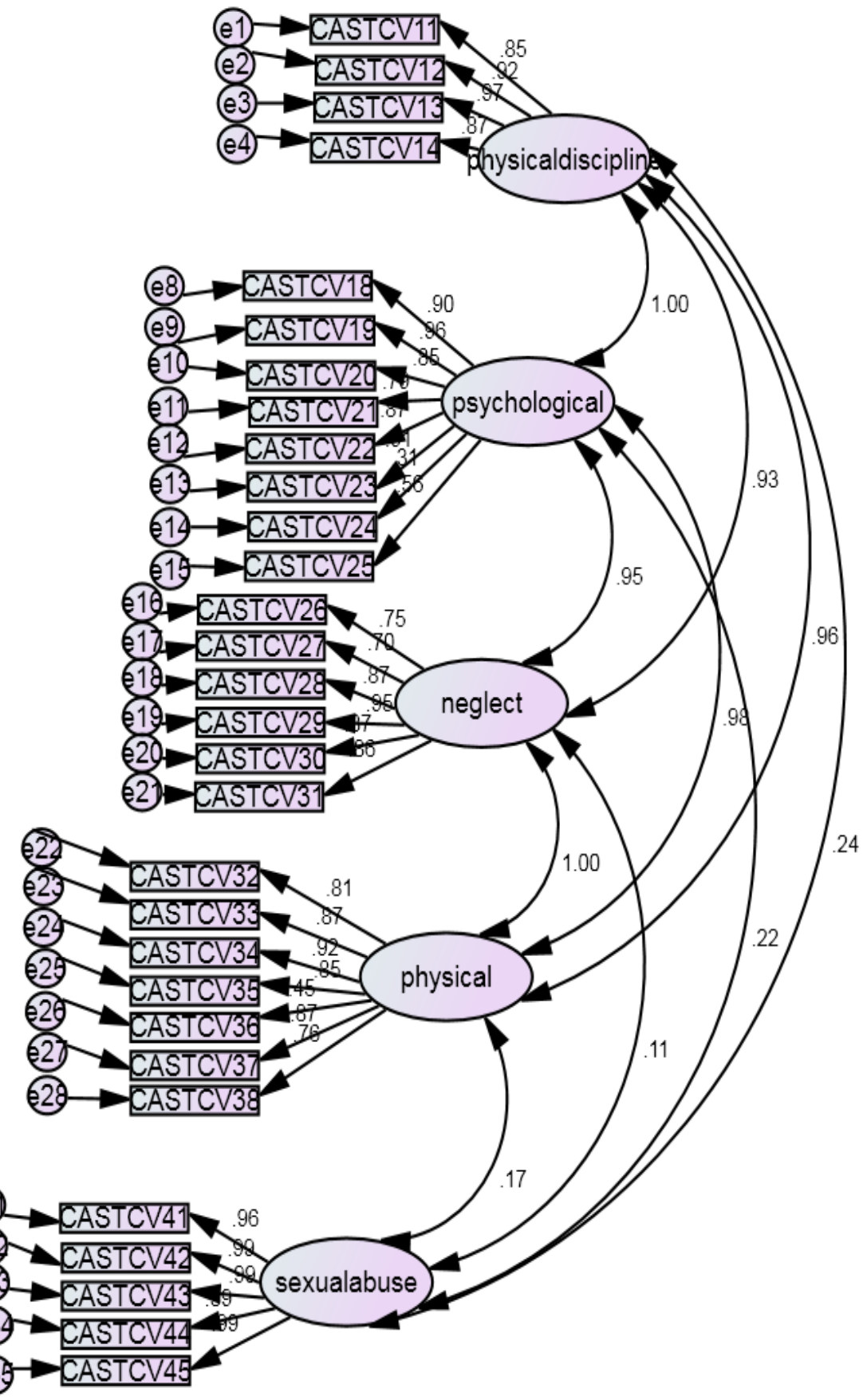

Figure 2: CFA model of ISPCAN Child Abuse Screening Tool (ICAST) 


\section{Discussion}

Investigating the historical backdrop of brutality in any given population includes resolving profoundly delicate issues. Since these issues might cause shame, self-fault and fear, concentrates on that guarantee the anonymity of members and try not to cause moral decisions about them to produce more dependable information and are probably going to benefit these individuals. Hence, concentrates on dependent on instruments that consider the social setting and don't uncover the members are more proper and solid.

The ICAST was created to empower worldwide child abuse appraisal. Multifaceted interpretation is required when an instrument is created in somewhere else and language and should be meant be applied locally. It requires changes in accordance with fit the objective culture rather than planning one more instrument in the language of the way of life. In the endeavor to decipher, the challenge is to get diverse invariance for the instrument, for example the scale ought to be invariant paying little mind to phonetic and social contrasts. The additional incentive for ICAST is that after culturally diverse interpretation and assessment of the instrument, five factor solution have been distinguished appropriate for the Pakistani culture.

The present study intended to translate and validate ISPCAN Child Abuse Screening Tool (CAST) in Urdu language. The factorial structure of ICAST was analyzed and its reliability was compared with the original version of scale. The inter item correlation was significant for Urdu translated scale and original ICAST. The internal consistency was determined through alpha reliability which indicates that Urdu ICAST was an adequate tool to screen children with different types of maltreatment in Pakistan. The reliability of ICAST and its subscales was better than the original reliability and studies conducted in other countries (Zolotar et. al, 2009; Finkelhor, et. al, 2005 \& Straus, et. al, 1998). The reliability coefficients of Urdu version of ICAST were high for validation process. The convergent and discriminant validity shows the construct validity of scale.

The five-factor model of ICAST was replicated on Pakistani children. The results support the five-factor model through CFA with adequate to reasonable model fit. The five factors are: physical discipline, psychological, physical abuse, neglect and sexual abuse as mentioned in the original scale. Although few items have low loadings but still it adequately fits the model indices. The studies based on instruments which highlight and reflect the cultural context are more appropriate and reliable. In conclusion, the translation and semantic validation of ICAST showed 
high reliability and validity and it also gave same factorial structure in CFA model as in original scale. Therefore, ICAST-Urdu is a reliable tool to use with Pakistani population. The ICAST has been validated in almost 20 languages depicting its reproducible ability which allow systematic comparison of data across cultures and research groups.

\section{Conclusion}

The present study supports the five-factor model of Urdu version of Child Abuse Screening Tool as reported in original CAST scale. Moreover, current findings show that the Urdu translated scale is a valid and reliable tool for screening abused children in Pakistan.

\section{Limitations and Suggestions}

The key limitation of the present study was small sample size as this sample might not represent the whole population of people of Pakistan. Therefore, future studies should look for more heterogeneous sample to enhance the generalizability of findings.

\section{Practical Implications}

The present study has many practical implications. First of all, the ICAST is a worldwide, multi-lingual, agreement-based review instrument. It is accessible in six languages for global exploration to gauge child maltreatment and abuse. Therefore, this tool serves as evaluating the prevelance of child exploitation and understanding the extent of the issue, defining national and local priorities, and collecting support for program and strategy advancement focused on child protection. Secondly, this can be used as a initial screening tool in schools for early identification of abuse and later intervention of behavioral problems associated with child abuse and neglect. 


\section{References}

Anderson, K. L. (2008). Child abuse. In L. Kurtz (Ed.), Encyclopedia of violence \& conflict ( $2^{\text {nd }}$ ed., pp. 197-211). Oxford: Academic Press.

ANI (November13, 2021). Child abuse Rampant in Pakistan: Report

Baker, A. W., \& Duncan, S. P. (1985). Child sexual abuse: A study of prevalence in Great Britain. Child Abuse \& Neglect, 9(4), 457-467. doi:10.1016/0145-2134(85)90054-7

Berliner, L., \& Elliott, D. M. (2002). Sexual abuse of children. In J. E. B. Myers, L. Berliner, J. Briere, C. T. Hendrix, T. Reid, \& C. Jenny (Eds.), The APSAC handbook on child maltreatment (2nd ed., pp. 5578). Newbury Park, CA: Sage Publications

Brown, P. (2012). Handbook of child sexual abuse: Identification, assessment, and treatment. New Jersey: John Wiley \& Sons, Inc.

Dunne, M, P., Zolotor, A, J., Runyan, D, K., Andreva-Miller, I., Choo, W, Y., Dunne, S, K., et al. (2009). ISPCAN Child Abuse Screening Tools Retrospective version (ICAST-R): Delphi study and field testing in seven countries. Child Abuse Negl, 33, 815-25.

Finkelhor, D., Ormrod, R. K., Turner, H. A., \& Hamby, S. L. (2005). Measuring poly-victimization using the Juvenile Victimization Questionnaire. Child Abuse and Neglect, 29(11), 1297-1312.

Flanagan, A. Y. (1998). Child abuse and neglect: What healthcare professionals need to know? Retrieved from www.nursingceu.com/NCEU/courses/childabuse

Forrester, D., \& Harwin, J. (2000). Monitoring children's rights globally: Can child abuse be measured internationally? Child Abuse Review, $9(6), \quad 427-438$. doi: http://dx.doi.org/10.1002/10990852(200011/12)9:6<427::AID-CAR661>3.0.CO;2-I

Gabbay, V., Oatis, M. D., Silva, R. R., \& Hirsch, G. S. (2004). Epidemiological aspects of PTSD in children and adolescents. In Silva, P. R (Ed.). Posttraumatic stress disorders in children and adolescents: Handbook (pp. 1-17). New York: W. W. Norton \& Company Inc.

Gilbert, R., Wisdom, C. S., Browne, K., Fergusson, D., Webb, E., \& Janson, S. (2009). Burden and consequences of child maltreatment in high-income countries. The Lancet, 373 (9657), 68-81. doi: 10.1016/S0140-6736(08)61706-7 
Goodman, G. S., Quas, J. A., \& Ogle, C. M. (2010). Child maltreatment and memory. Annual Review of Psychology, 61, 325-351. doi: 10.1146/annurev.psych.093008.100403

Herman, J. L. (1997). Trauma and recovery. (p. 367). New York: Basic Books.

Hillis, S., Anda, R., Dube, S., Felitti, V., Marchbanks, P., \& Marks, V. (2004). The associations between adverse childhood experiences and adolescent pregnancy, long-term psychosocial consequences, and fetal death. Pediatrics, 113(2), 320-327.

Howard, B. J. (1996). Advising parents on discipline: what works. Pediatrics, 1996 (98), 809-815.

Hornor, G. (2010). Child sexual abuse: Consequences and implications. Journal of Paediatric Health Care, 24(6), 358-364. doi:10.1016/j.pedhc.2009.07.003

Johnson, G. J., Cohen, P., Smailes, E. M., Skodol, A. E., Brown, J., Oldham, J. M. (2001). Childhood verbal abuse and risk for personality disorders during adolescent and early adulthood. Comprehensive Psychiatry, 42(1), 16-23.

Kent, A., \& Waller, G. (1998). The impact of childhood emotional abuse: An extension of the child abuse and trauma scale. Child Abuse \& Neglect, 22(5), 393-399.

Lalor, K. (2004). Child sexual abuse in Tanzania and Kenya. Child abuse \& neglect, 28(8), 833-844. doi: 10.1016/j.chiabu.2003.11.022

Lamper, L. (2003). How to stop yelling. http://www.parents.com/articles /ages_and_stages/3214.jsp

MAPI Institute (2012). Linguistic Validation Manual for Health Outcome Assessments, $2^{\text {nd }}$ Ed. ed. Lyon: MAPI Research Trust.

Malik, F., \& Saeed, S. (2014). Revision and validation of the child abuse scale (CAS). Unpublished MPhil thesis, Department of Psychology, GC University, Lahore.

Malik, F. D, \& Shah, A. A. (2007). Development of Child Abuse Scale: Reliability and Validity analyses. Psychology and Developing Societies, 19(2), 161-178. 
Mckay, M., Fanning, P., Paley, K., \& Landis, D. (1996). When anger hurts your kids: A parent's guide. Oakland, CA: New harbinger Publications, Inc.

Moffatt, G. K. (2003). Wounded innocents and fallen angels: Child abuse and child aggression. California: ABC-CLIO, Inc.

National Statistics on Child Abuse. (2015). National Child Abuse Statistics collected from Children's Advocacy Centres 2011 and 2012. Retrieved from http://www.nationalchildrensalliance.org/ncanationalstatistics

Ney, P. G. (1987). Does verbal abuse leave deeper scars: A study of children and parents. Canadian Journal of Psychiatry, 32, 371-378.

Olive, M. F. (2007). Child abuse and stress disorder. New York, NY: Infobase Publishing

Pierce, L., \& Bozalek, V. (2004). Child abuse in South Africa: an examination of how child abuse and neglect are defined. Child Abuse \& Neglect, 28(8), 817-832.

Pinheiro, P. (2006). World report on violence against children. New York: United Nations' Secretary General's study on violence against children.

Rich, C. L., Gidyez, C. A., Warketin, J. B., Loh, C., \& Weiland, P. (2005). Child and adolescent abuse and subsequently victimization: A prospective study. Child Abuse \& Neglect, 29(12), 1373-1394.

Runyan, D., Wattam, C., Ikeda, R., Hassan, F., \& Ramiro, L. (2009). Child abuse and neglect by parents and other caregivers. In: Krug E, Dahlberg LL, Mercy JA, Zwi AB, Lozano R, editors. World report on violence and health. Geneva, Switzerland: World Health Organization; p. 59-86. Available from: http://www.who.int/violence_injury_prevention/violence/global_cam paign/en/chap3.pdf

Selengia, V., Thuy, H, N., Mushi, D. (2020). Prevelance and patterns of child sexual abuse in selected countries of Asia and Africa: A review of literature. Open Journal of Social Sciences, 8(9), 146-160. DOI: 10.4236/JSS.2020.89010.

Silveira, A., \& Grassi-Oliveira, R. (2016). Semantic validation of the ISPCAN child abuse screening tools (ICAST) in Brazilian Portuguese. Trends in Psychiatry and Psychotherapy, 38(2),105-110. DOI:10.1590/2237-6089-2016-0012. 
Smith, P. (2016). Cognitive processing and biases in stroop task and event related potential stimulus. Child Abuse and Neglect, 32(7), 97-120.

Society for the Protection of the Rights of the Child. (SPARC, 2015). State of Pakistan's Children Report 2015. Retrieved from http://www.sparcpk.org/2015/SPARCNews.

Teicher, M. H., Samson, J. A., Tomoda. A., Ashy, M., \& Anderson, S. L. (2007). Neurobiological and behavioral consequences of exposure to childhood traumatic stress. In E. R. Arnetz B. B. (Ed.), Textbook on Stress, Germany: Wiley-VCH.

Teicher, M. H., Dumont, N. L., Ito, Y., Vaituzis, C., Giedd, J. N., \& Andersen, S. L. (2004). Childhood neglect is associated with reduced corpus callosum area. Biological Psychiatry, 56(2), 80-85. doi: 10.1016/j.biopsych.2004.03.016

Trivedi, A. (2013). Sri Lanka struggles to contain a growing epidemic of child abuse. Archives of General Psychiatry, 62(8), 922-933. doi:10.1001/archpsyc.62.8.922.

UNICEF. (2016). Child protection from violence, exploitation and abuse. Retrieved from http://www.unicef.org/protection/57929_child_labour.html

U.S. Department of Health and Human Services. (2016). Administration for Children and Families. Child maltreatment 2014. Washington, DC: US Retrieved from http://www.acf.hhs.gov/

Walker, W. (2003). Teaching parents about their children. The Philadelphia Inquirer, p, L4.

Williamsons, D. F., Thompson, T. J., Anda, R, F., Dietz, W. H., \& Felitti, V. (2002). Body weight and obesity in adults and self-reported abuse in childhood. International Journal of Obesity, 26, 1075-1082.

Wozencraft, T., Wagner, W., \& Pellegrin, A. (1991). Depression and suicidal ideation in sexually abused children. Child Abuse \& Neglect, 15(4), 505-511. doi: 10.1016/0145-2134(91)90034-B

World Health Organization, (2002). Child abuse and neglect by parents and other caregivers. In world report on violence and health (chap.3). Retrieved from http://whqlibdoc.who.int/hq/2002/9241545615.pdf 
Zolotor, A. J., Runyan, D. K., Dunne, M. P., Jain, D., Péturs, H. R., Ramirez, C., Volkova, E., Deb, S., Lidchi, V., Muhammad, T., Isaeva, O. (2009). ISPCAN Child Abuse Screening Tool Children's Version (CAST): Instrument development and multi-national pilot testing. Child Abuse \& Neglect, 33(11), 833-41. doi: 10.1016/j.chiabu.2009.09.004.

Citation of this Article:

Iftikhar, R., \& Malik, F. (2021). Psychometric testing and semantic validation of (ISPCAN) child abuse screening tool (ICAST) in Urdu

language. Pakistan Journal of Education, 38(2), 91-131. 